\title{
Preliminary study on occurrence of composite material delamination processed by abrasive water jet cutting
}

\author{
Ioan Alexandru Popan ${ }^{1, *}$, Nicolae Bâlc ${ }^{1}$, and Alina Ioana Popan ${ }^{1}$ \\ ${ }^{1}$ Technical University of Cluj-Napoca, B-dul. Muncii, No. 103-105, Cluj-Napoca, Romania
}

\begin{abstract}
The paper presents a preliminary experimental study on processing composite materials (CFRP) using abrasive water jet cutting (AWJC) process, analysing the possibilities of occurrence of material delamination. AWJC is a proper solution for cutting CFRP because of reduced interface temperature, high flexibility, low mechanical loading and reduced cutting forces. Cutting CFRP using AWJC involves several challenges like material delamination due to the high velocity impact of the jet. To understand the delamination, three experimental tests were made: in the first test the cutting and the drilling was made with high water pressure $(350 \mathrm{MPa})$, in the second test the cutting was made with high water pressure and for drilling was used low water pressure (200 MPa) and in last test a pre-drilled hole was used. Within those experiments was observed the CFRP delamination appears just during the drilling, not during the cutting. By decreasing the water jet pressure, the jet energy is decreased and in this way the delamination decrease.
\end{abstract}

\section{Introduction}

A wide range of composite materials (Carbon Fibre Reinforced Plastics - CFRP) are used for many industrial applications. The main characteristics of CFRPs are: high strength to weight ratio, high modulus, high fracture toughness, corrosion and thermal resistance [1]. These materials have wide applications in aerospace, automotive, marine goods, etc. [2].

AWJ cutting is a good solution for processing CFRP because of reduced interface temperature, low mechanical loading, better surface integrity, low tool wear, and small cutting forces [3-5]. The AWJC uses pressurized water, which acts either by itself at a very high pressure, or in connection with the erosion of the abrasive particles, added into the water jet [6-7].

Figure 1 illustrates the main components of the AWJ head, including the mixing tube, where the pressurized water jet is mixed together with abrasive particles, which are needed for metals cutting.

\footnotetext{
* Corresponding author: ioan.popan@tcm.utcluj.ro
} 


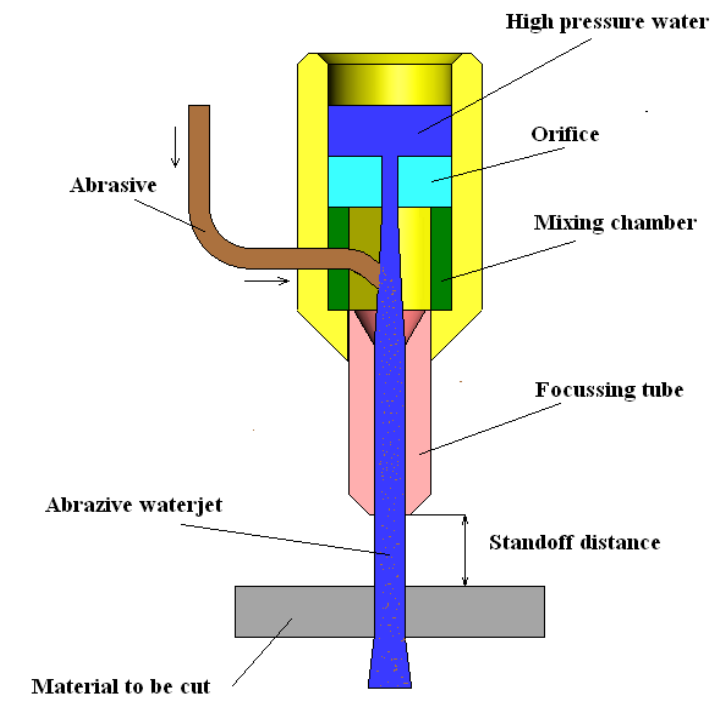

Fig. 1. AWJ head [6]

The AWJ working principle is based on a very high pressure water jet, which takes the abrasive particles into the mixing chamber, in order to create a cutting device [6-7].

Cutting composite materials using AWJC involves several challenges. The most important problem is material delamination due to the high velocity impact of the jet [4-5]. In figure 2 is illustrated the delamination in case of CFRP [8].

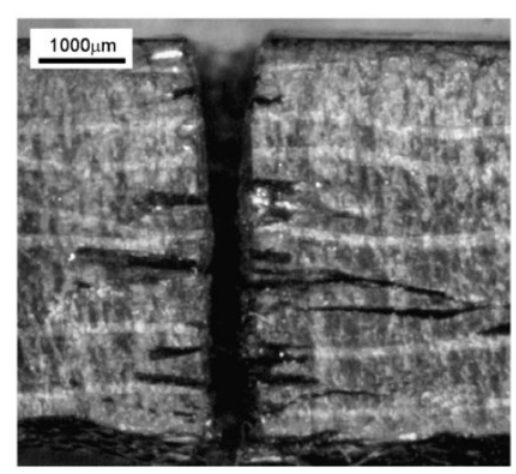

Fig. 2. Delamination effect [8]

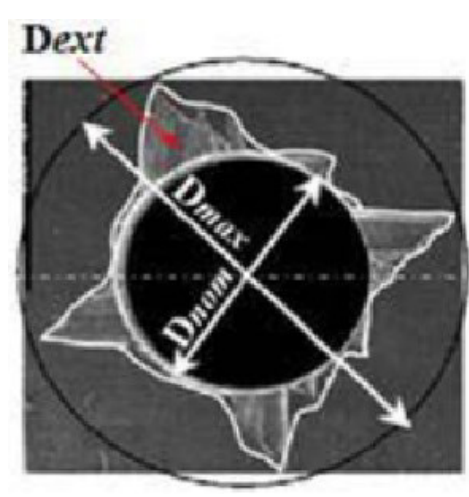

Fig. 3. Typical image for the visualization of the damage [10]

In figure 3 is presented a sketch for visualization of the damage evaluated by DeFu et al. (2012). The delamination extent $\left(\mathrm{D}_{\text {ext }}\right)$ is defined as a difference between the maximum diameter $\left(D_{\max }\right)$ of the damaged zone and the nominal exit hole diameter $\left(D_{\min }\right)$ [9-10].

To minimise the composite material delamination, a starter hole can be made, but this introduce time consuming and extra costs [11].

This paper presents an experimental investigation on delamination of composite materials during the AWJ cutting process. 


\section{Experimental procedure}

The material used in this study is a multi-layer composite material consisting of carbon fiber reinforced plastics (CFRP): a biaxial balanced carbon fibber material, of $200 \mathrm{~g} / \mathrm{m}^{2}$, plain-weave 5 layers in epoxy resin, type Epiphen RE4020 for the matrix produced by Bostic. In the case of the material, $50 \%$ of filaments are orientated along the longitudinal direction, while the remaining of $50 \%$ is oriented along the transverse direction [7].

The experimental trials have been conducted on a 3-axis, Omax 2626 abrasive waterjet system (Figure 5). It is equipped with an OMAX high pressure pump with an output pressure of maximum $400 \mathrm{MPa}$. The CNC Omax controller can move the cutting head in 3 axis simultaneous with maximum $4500 \mathrm{~mm} / \mathrm{min}$.

The constant parameters used on this study are: orifice diameter (diamond) $0.35 \mathrm{~mm}$, nozzle tube diameter $0.76 \mathrm{~mm}$, nozzle length $101.65 \mathrm{~mm}$, abrasive type Australian Garnet mesh size 80, impingement angle $90^{\circ}$ and standoff distance $2 \mathrm{~mm}$.

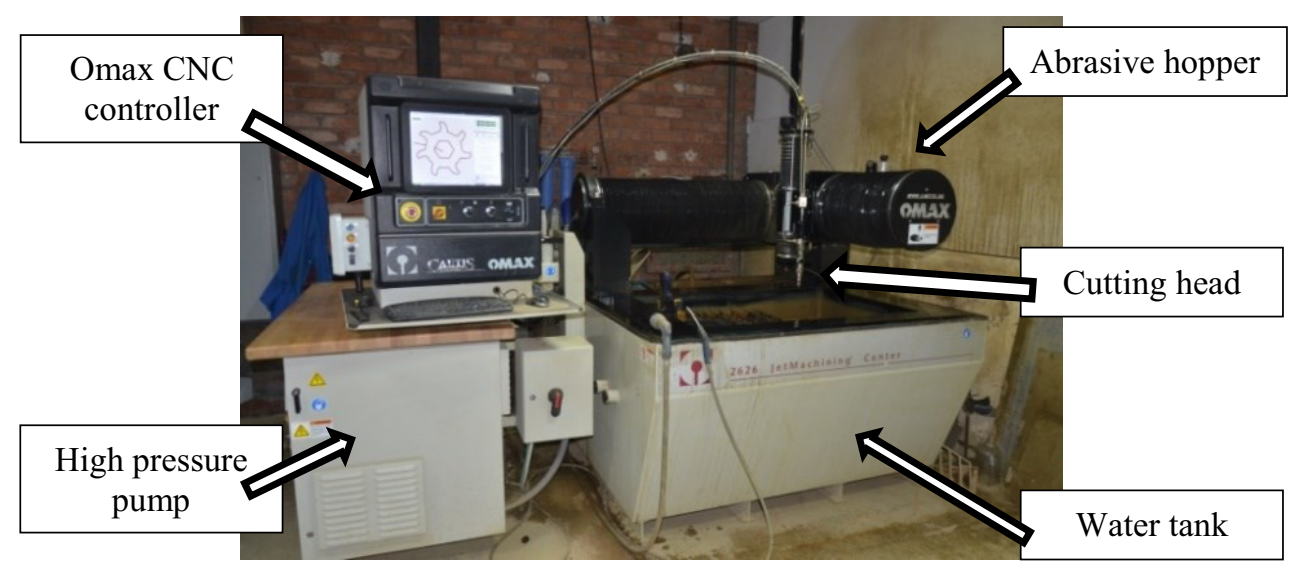

Fig. 5. AWJ equipment, Omax 2626.

The 2D cutting sketch was designed in the Omax Layout software. The part origin was selected in the centre of the part. Another step on process setup was choosing the lead In/Out. The lead In/Out was choose automatically within this application and was selected just the length of lead In of $15 \mathrm{~mm}$, to avoid the material delamination on drilling point (figure 6).

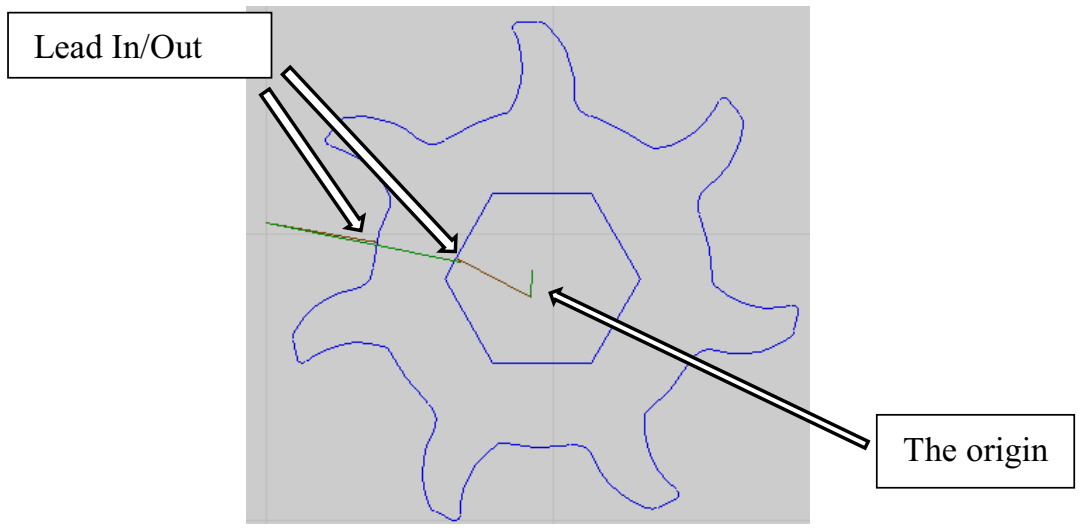

Fig. 6. The origin and the lead In/Out points. 
In this experimental study was analysed the possibility to occur the delamination during the processing composite materials in three cases:

$\mathrm{i}$ : In the first case for the cutting and drilling processes was used with high water pressure.

For processing the part were selected the following process parameters: cutting speed $\mathrm{V}=300 \mathrm{~mm} / \mathrm{min}$; water pressure: $\mathrm{P}=350 \mathrm{MPa}$ and abrasive flow rate: $\mathrm{M}_{\mathrm{a}}=0.45 \mathrm{Kg} / \mathrm{min}$.
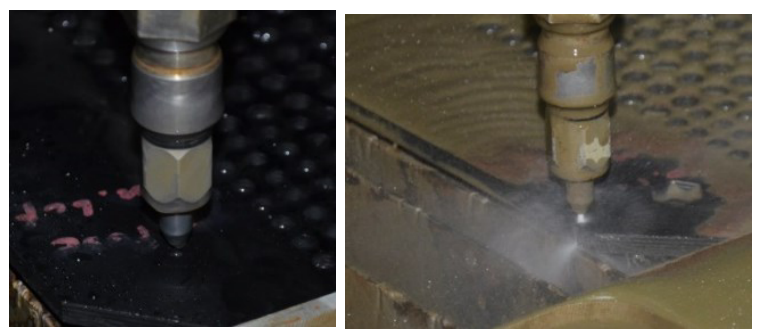

Fig. 7. The part made using pre-drilled hole.

ii: In second case for the cutting process was used a high water pressure and for drilling a low water pressure .

The selected process parameters are: cutting speed $\mathrm{V}=300 \mathrm{~mm} / \mathrm{min}$; water pressure for cutting: $\mathrm{P}=350 \mathrm{MPa}$; water pressure for drilling: $\mathrm{P}=200 \mathrm{MPa}$, abrasive flow rate: $\mathrm{Ma}=0.45$ $\mathrm{Kg} / \mathrm{min}$.
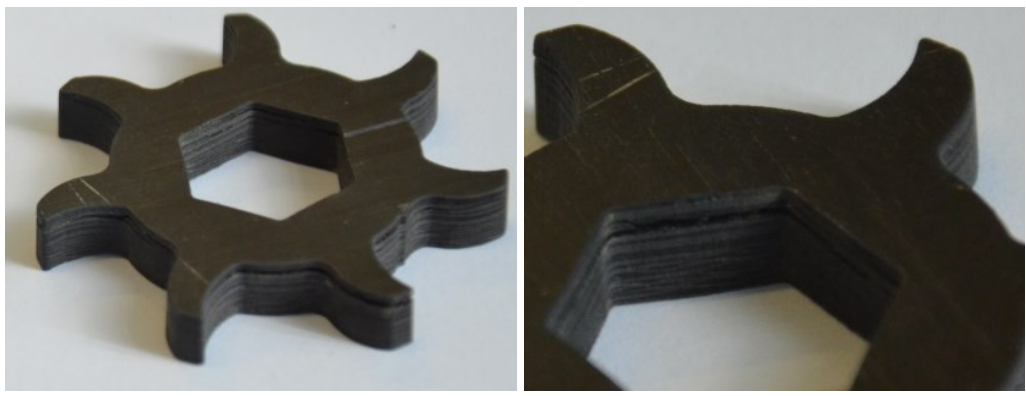

Fig. 8. The part made only with AWJC.

iii: In third case a pre-drilled hole was used.

To avoid the composite material delamination in the drilling point, a $6 \mathrm{~mm}$ hole was made. This hole was made by using a carbide drill. In figure 9 is illustrated the drilling process and the hole. The process parameters are similar to those used in the second experimental case.
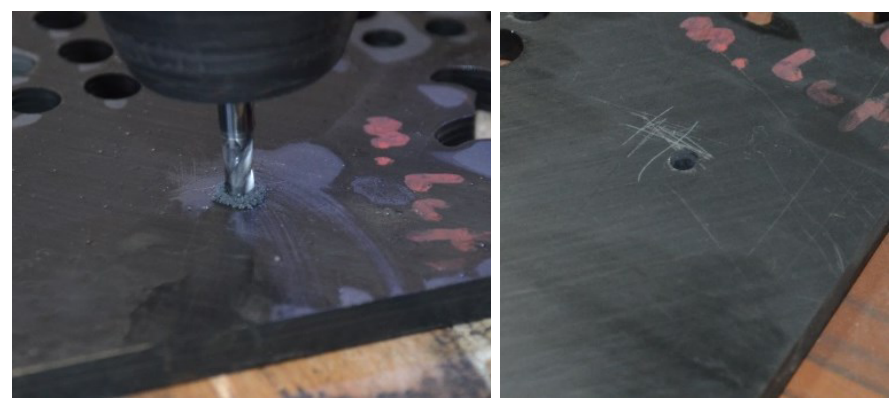

Fig. 9. The pre-drilled hole. 

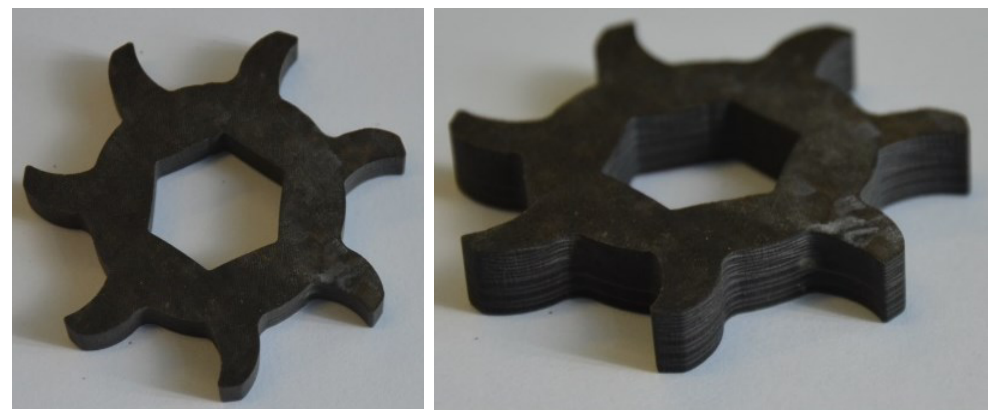

Fig. 10. The part made using pre-drilled hole.

\section{Results and discussions}

The maximum extent of delamination up to $60 \mathrm{~mm}$, was obtain during the drilling of CFRP using abrasive water jet at high pressure $350 \mathrm{MPa}$. This powerful delamination effect results in splitting the part into two pieces, destroying the part (figure 11).

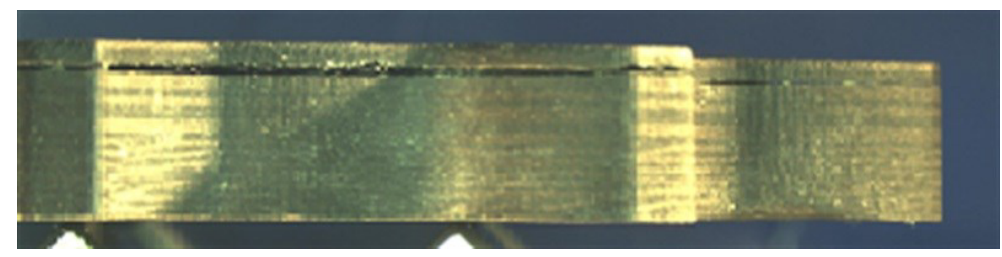

Fig. 11. The part drilled using abrasive water jet at high pressure $350 \mathrm{MPa}$.

In figure 12 is illustrated an image of the drilled part using abrasive water jet at low pressure $200 \mathrm{MPa}$ and cut with a high pressure $380 \mathrm{MPa}$.

On this case study the maximum extent of delamination was $5 \mathrm{~mm}$ and abrasive embedment do not appear.

It can be observed by decreasing the water pressure from $380 \mathrm{MPa}$ up to $200 \mathrm{MPa}$ the extent of delamination decreasing from $60 \mathrm{~mm}$ up to $6 \mathrm{~mm}$, during the drilling process.

This proves that by decreasing the water jet pressure, the jet energy is decreasing and in this way the delamination can be avoided.

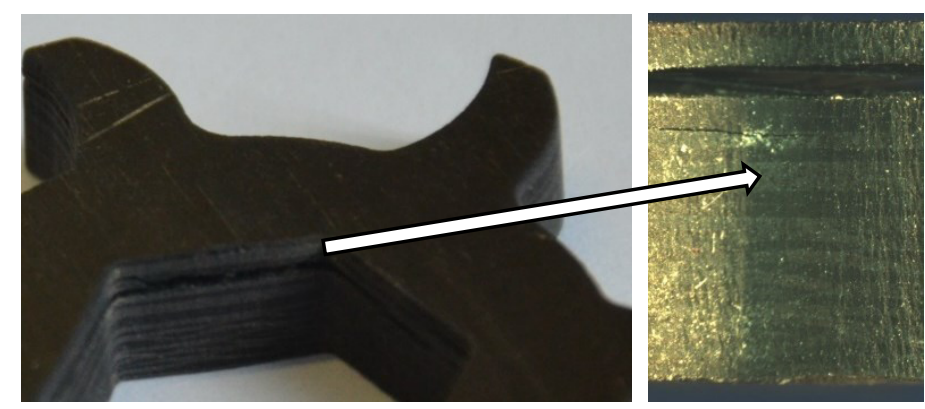

Fig. 12. The part drilled using abrasive water jet at low pressure 200MPa.

In figure 13 is illustrated a microscopic image of the part manufactured onto the third experiment.

In this case the material delamination and abrasive embedment do not appear. In this experiment the abrasive jet doesn't hit the material during the drilling process, because of 
start point a starter hole was made. This proves that due to the high velocity impact of the jet during the drilling the delamination appears.

In conclusion the delamination does not appear during the cutting process only during the drilling process.

In the case of using a starting hole the material delamination can be avoided. An extra cost is the main disadvantage to use a pre-drilled hole during the cutting complex parts from composite materials. Ramulu and Kraja (2002) obtained the same results in their studies in minimization the delamination by using a pre-drilled hole.

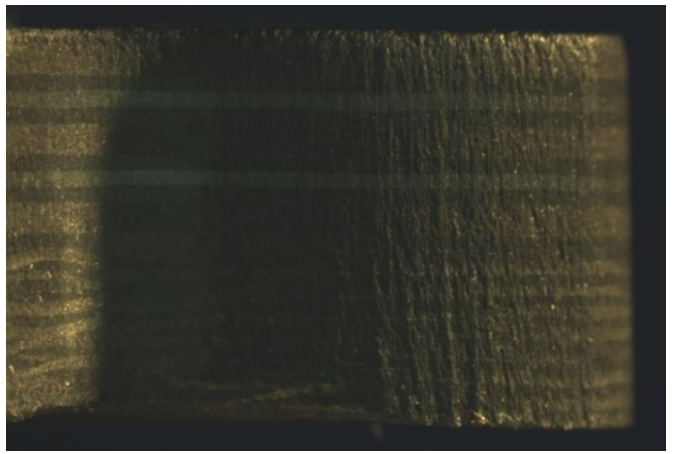

Fig. 13. The part made using pre-drilled hole.

Measuring the parts dimensions a good dimensional accuracy of $\pm 0.05 \mathrm{~mm}$ was obtained.

Analysing the part contours was observed a shape deviation in the cutting starting and ending points. This shape error is illustrated in figure 14. The dimension of this over cut was $0.2 \times 1 \mathrm{~mm}$. To obtain precise parts from CFRP manufacture using AWJ cutting this effect must be analysed. This type of defects can lead to a damaged part. [12]

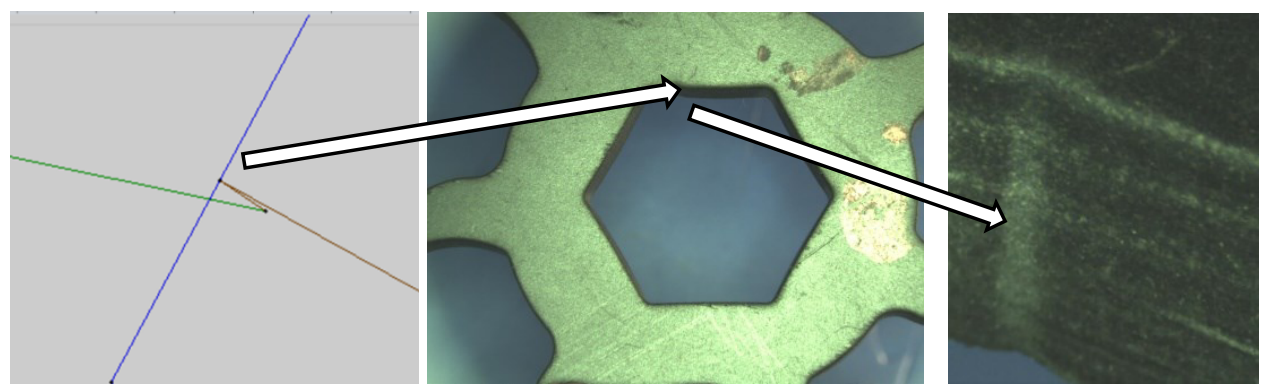

Fig. 14. The cutting start and end error.

\section{Conclusions}

This paper presents a preliminary study regarding the possibilities of delamination occurrence in case of CFRP materials manufacture using abrasive water jet cutting.

The specific conclusions from this experimental study are:

- The maximum extent of delamination, $60 \mathrm{~mm}$, was obtain during the drilling of CFRP using abrasive water jet at high pressure of $350 \mathrm{MPa}$.

- Decreasing the water jet pressure during the drilling, up to $200 \mathrm{MPa}$, the maximum extent of delamination was $5 \mathrm{~mm}$. 
- Decreasing the water jet pressure, the jet energy is decreased and in this way the delamination is decreasing. Using the optimal process parameters the delamination can be avoided.

- Using a starter hole the material delamination can be $100 \%$ eliminated. The main disadvantage of this solution is that an extra operation is introduced, this means extra costs.

- The CFRP delamination appears just during the drilling, not during the cutting process.

- In the cutting "start" and "end" points a shape deviation (an over cut) was observed. This shape error has the dimensions of $0.2 \times 1 \mathrm{~mm}$.

The research was supported within the PreMCo project (Bridge Grant No. 99BG/2016), PN-3-P2 UEFISCDI.and the H2020 AMaTUC project (GA 691787).

\section{References}

1. A. Popescu, L. Hancu, P. Bere, Applied Mechanics and Materials 371, 394 (2013)

2. E. Lemma, F. L. Chen, Compos Struct; 57, 297 (2002)

3. P. Hreha, A. Radvanská, Metalurgija 53 (4), 533 (2014)

4. A. Filip, M.Vasiloni, MATEC Web of Conferences 94, 03003 ( 2016)

5. J. Wang, Int J Adv Manuf Technol, 15, 757 (1999)

6. A. Popan, N. Balc, Academic journal of manufacturing engineering, 7(1), 17 (2009)

7. A. Miron, A. Popan, Studies on water jet cutting of 2D parts made from carbon fiber composite materials, IMANE (2013)

8. D.K. Shanmugam, Composites: Part A 39 (6), 923 (2008)

9. D. Liu, Y. Tang and WL. Cong, Composite Structures 94, 1265 (2012)

10. M. Ramulu, S.Kraja, $33^{\text {rd }}$ International SAMPE Proceedings, 33, 1327 (2002)

11. K. Phapale, R. Singh, Procedia Manufacturing 5, 521 (2016)

12. M. Harničárová, J. Valíček, R. Čep, J. Petrů, L. Čepová, Surface integrity analysis in laser beam cutting process, Metal, Brno, Czech Republic, EU (2013) 